\title{
Lewis blood group and CEA related antigens; coexpressed cell-cell adhesion molecules with roles in the biological progression and dissemination of tumours
}

\author{
D S A Sanders, M A Kerr
}

\begin{abstract}
The Lewis blood group and carcinoembryonic antigen (CEA) related antigens have adhesive functions in human tissues, with roles in embryonic sorting and migration of cells (organogenesis), differentiation and protection of normal mucosal tissues, migration of neutrophils, bacterial binding, and tumour differentiation and dissemination. In the key areas of mucosal protection, neutrophil binding, and tumour metastasis, they are often coexpressed on the outer cell membrane, with Lewis blood group antigens forming the terminal carbohydrate chains on a CEA related glycoprotein backbone. The central role of these antigens in the mechanism of neutrophil binding to endothelium in inflammation highlights a fascinating paradigm for tumour cell dissemination and metastasis, and expression is linked to disease prognosis. This review outlines the structure, function, and comparative roles of these antigens in human tissues.

(F Clin Pathol: Mol Pathol 1999;52:174-178)
\end{abstract}

Keywords: carcinoembryonic antigen; Lewis; sialyl Lewis ${ }^{\mathrm{x}}$; adhesion; squamous; carcinoma

The combinatorial expression of large numbers of cell adhesion molecules (CAMs) and integrins on the cell surface, with complex and variable pathways responsible for the expression of a single CAM, has the important property of robustness; no deletion of a simple component or pathway would be expected to result in loss of function (that is, adhesion). The immense diversity of signals to which a cell must respond requires a broad variety of cell surface molecules, many of which are glycoproteins for reasons that are physiologically and biologically appealing. A polypeptide (such as carcinoembryonic antigen (CEA)) normally forms the backbone inserted into the cell membrane on to which bind a limited number of sugars. Although limited, the opportunities for branching and for differing distributions on a given polypeptide allow for an enormous number of possible structures. The glycosyl portion of glycoproteins is constructed by the addition of monosaccharides or oligosaccharides to a growing chain at specific attachment sites. The first of two types of linkage found in membrane glycoproteins is between asparagine and $\mathrm{N}$-acetylglucosamine, the second is between serine or threonine and $\mathrm{N}$-acetylgalactosamine. It is not uncommon for the 0 -glycosidically linked carbohydrate chains to bear blood group antigens.

Often, the most peripheral carbohydrate structures are fucose and/or sialic acid residues, which are, as a rule, terminal nonreducing ends that provide a stop signal for further glycosylation. The Lewis blood group antigens are an example of fucosylated glycoconjugates. ${ }^{1}$

\section{Lewis blood group antigens}

The so called blood group antigens, a family of cell surface carbohydrate structures, were originally discovered on the surface of erythrocytes. It was clear early on that these antigens were also present in many extraerythroid tissues throughout the body. Much of the recent interest in these antigens has resulted from the observation that they undergo specific changes during tissue embryonic development and, less predictably, during malignant transformation.

Lewis blood group antigens are structurally related to the major blood group histocompatibility antigens $\mathrm{ABH}$. The expression of Lewis antigens on erythrocytes is determined by the interaction of the Lewis gene with the $\mathrm{H}$ and secretor genes. Unlike the $\mathrm{ABH}$ antigens, the Lewis antigens on erythrocytes are passively acquired from glycolipid substances in the serum that are synthesised at an unknown site, whereas the $\mathrm{H}$ antigen is under the influence of the secretor gene. Lewis ${ }^{a}\left(\mathrm{Le}^{\mathrm{a}}\right)$ and Lewis ${ }^{\mathrm{b}}\left(\mathrm{Le}^{\mathrm{b}}\right)$ also occur in secretions, such as saliva and gastric mucous, on the same glycoprotein molecules that carry the $\mathrm{ABH}$ determinants in secretions. Therefore, Lewis blood group antigens occur on a variety of secretory epithelia and also on non-secretory cells, where it has not been determined whether expression is by synthesis or passive acquisition. The structural relation between the Lewis blood group and tumour associated antigens is shown in fig 1

One of the most widely studied tumour associated antigens has been the Lewis ${ }^{x}\left(\operatorname{Le}^{x}\right)$ antigen, designated $\mathrm{CD} 15$ by the "first international workshop on human leukocyte differentiation antigens", which is a marker of human granulocytes and some stages of myeloid leukaemia. The antigenic determinant recognised by several antigranulocyte monoclonal antibodies has been shown by radioimmunoassay to involve 3-fucosyl- $N$-acetyl-lactosamine, first identified as lacto-fucopentose III, a carbohydrate found
Accepted for publication 11 March 1999 
Type 1 chains

\begin{tabular}{|c|c|c|c|c|}
\hline Galß1-3GIcNac- & \multicolumn{2}{|c|}{ Galß1-3GIcNac- } & \multicolumn{2}{|c|}{ Galß1-3GIcNac- } \\
\hline I & I & I & I & I \\
\hline I & I & I & I & I \\
\hline Fuc $\alpha 1-4$ & Fuc $\alpha 1-2$ & Fuc $\alpha 1-4$ & NeuAc $\alpha 2-3$ & Fuc $\alpha 1-4$ \\
\hline Lewis $^{a}$ & \multicolumn{2}{|c|}{ Lewis $^{b}$} & \multicolumn{2}{|c|}{ Sialyl Lewis ${ }^{a}$} \\
\hline
\end{tabular}

Type 2 chains

Galß1-4GIcNac-

Galß1-4GlcNac-

Galß1-4GIcNac-
|
|

Fuc $\alpha 1-3$

Fuc $\alpha 1-2$ Fuc $\alpha 1-3$

NeuAc $\alpha 2-3$

Fuc $\alpha 1-3$

Lewis $^{x}$

Lewis $^{Y}$

Sialyl Lewis ${ }^{x}$

Figure 1 The relation between Lewis ${ }^{a}$, Lewis $^{b}$, and other blood group or tumour associated antigens.

in human milk and on adenocarcinoma cells. The first monoclonal antibody to recognise this antigen, anti-stage specific embryonic antigen (SSEA), was in fact raised against a mouse teratocarcinoma cell line, and since then many antibodies raised against lung cancer and adenocarcinoma of stomach and colon have been shown to recognise the same antigen. 3-Fucosyl- $N$-acetyl-lactosamine may be the immunodominant antigen on many carcinomas, but is also expressed in a wide range of normal human tissues. ${ }^{23}$ However, the fact that the antigen is present in a range of tissues does not detract from its usefulness in tumour diagnosis and staging.

FUNCTION

Examination of $\mathrm{Le}^{\mathrm{a}}$ in fetal tissues has been shown to be stage specific, correlating with similar findings made on its type 2 chain positional isomer $\mathrm{Le}^{\mathrm{x}},{ }^{4}$ suggesting a functional similarity between these carbohydrate structures. The $\mathrm{Le}^{\mathrm{x}}$ residue has been suggested to be a mediator of the cation dependent, homotropic adhesion of mouse embryonic cells, and might play an important role in controlling cell recognition during cell aggregation and embryological development. ${ }^{5}$ In the developing cerebellum, the $\mathrm{Le}^{\mathrm{x}}$ antigen is increasingly found in the molecular layer during migration of granule cells. ${ }^{2}$ Antibodies to the antigen can modify cell migration in the developing cerebellum. ${ }^{26}$ This evidence hinted at the exciting possibility that these antigens might be part of a family of cell surface molecules involved in the intercellular adhesion mediating embryonic organisation of tissues, granulocyte adhesion and migration, and tumour invasiveness.
More recent work has reinforced this theory and has confirmed the structural and functional link between $\mathrm{Le}^{\mathrm{a}}$ and $\mathrm{Le}^{\mathrm{x}}$. Granulocyte and platelet adherence to activated endothelium is now recognised to be mediated through the upregulation of sialated $\mathrm{Le}^{\mathrm{x}}$ (CA19-9) on the surface, which binds to the endothelial ligand ELAM-1 (endothelial leucocyte adhesion molecule 1). ${ }^{7}$ Polymorph adhesion and extravasation may be a paradigm for tumour cell dissemination because adenocarcinoma cell lines express sialated $\mathrm{Le}^{\mathrm{x}}{ }^{8}$ In addition, tumour necrosis factor stimulates endothelium to express ELAM-1. ${ }^{9}$ ELAM-1 has been shown to recognise an antigenic determinant common to $\mathrm{Le}^{\mathrm{a}}$ and $\mathrm{Le}^{\mathrm{x}},{ }^{10}$ and most recently it has been shown that tumour cell adhesion can be mediated through the sialated forms of both $\mathrm{Le}^{\mathrm{a}}$ and $\mathrm{Le}^{\mathrm{x}} .^{11} 12$

Liver endothelial ELAM-1 mediates carcinoma cell adhesion through sialyl Lewis ${ }^{\mathrm{x}}{ }^{13}$ expression of sialyl Lewis ${ }^{\mathrm{x}}$ is related to colorectal cancer metastasis, ${ }^{14}$ and serum levels relate to survival in non-small cell lung carcinoma. ${ }^{15}$

\section{Carcinoembryonic antigen}

CEA was first reported by Gold and Freedman in $1965,{ }^{16}{ }^{17}$ and independently by von Kleist and Burtin in $1969,{ }^{18}$ as being present in fetal gut and colonic tumours but not in normal tissues; that is, it was put forward as an oncofetal antigen. CEA was later found in normal body fluids and in normal mucosa, and the clinical application of CEA became complicated because it was recognised that a number of closely related crossreacting antigens showed variable expression patterns in a variety of normal tissues. ${ }^{19}$ The monitoring of serum CEA concentrations, which are grossly raised at the time of diagnosis but lowered after treatment, remains an important clinical parameter in the follow up of patients with colonic cancer. Raised CEA values have also been reported in other epithelial malignancies such as those of the breast, lung, and pancreas. ${ }^{20}$

Recent advances in molecular genetics have led to radical improvements in the understanding of the complex expression patterns of CEA and its related crossreacting antigens, which has led to reassessment of the clinical outlook for CEA and has given insight into the possible functions of these molecules. Molecular cloning has identified a number of CEA related genes and splice variants of genes that encode CEA. In the past, only non-specific polyclonal antisera were available to workers but the recent development of monospecific anti-CEA and anti-NCA (non-specific crossreacting antigen) monoclonal antibodies, which may react with the surface of tumour cells, has rekindled the clinical usefulness of this molecule because of the ability to immunolocalise CEA expressing tumours and their metastases and to target the cells for immunotherapy ("magic bullets"). ${ }^{21}$ Radioimmunogold surgery with radiolabelled monoclonal anti-CEA antibodies is reported to improve the efficacy of second look surgery in colorectal cancer. ${ }^{22}$

Anti-CEA antibodies are now designated CD66, with a subclassification a-e, depending 
on which epitope of the antigen is recognised. For example, true CEA (CD66e), the classic crossreacting antigens such as non-specific crossreacting antigen 90 (NCA90; CD66c), and biliary glycoprotein 1 (BGP1; CD66a). Post-translational modifications of CEA related glycoproteins, such as differential glycosylation, vastly increase the already complex antigenic profile of these molecules.

The recognition that CEA related molecules are members of the C-2 set of cell adhesion molecules, which includes intercellular adhesion molecule 1 (ICAM-1) and ICAM-2 led to tests for adhesion for CEA. In structure and function they are similar to immunoglobulins. All CEA molecules have a leader (L) domain of 34 amino acids, necessary to direct nascent proteins through the endoplasmic reticulum for insertion into the plasma membrane or secretion. The backbone is made of a number of immunoglobulin-like domains. The domain number, in conjunction with differential glycosylation, accounts for the large size differences and molecular weights of the related glycoproteins.

FUNCTION

As for immunoglobulins, the adhesive properties of the CEA family are neither calcium nor temperature dependent and may be homophilic (CEA to CEA) or heterophilic (CEA to NCA). Adhesion is capacitated by the membranous localisation on tissue cells and, in this respect, the adhesive properties of true CEA, NCA, and BGPs are well recognised; however, this is not the case for pregnancy specific glycoprotein (PSG), most of which is secreted into the serum rather than being membrane bound. The adhesive strength of these molecules, based on the speed of aggregation and size of aggregates, is in the order $\mathrm{CEA}>\mathrm{NCA}>\mathrm{BGP}^{23}{ }^{24} \mathrm{CEA}$ related antigens have a role in binding Escherichia coli to the normal gut, ${ }^{25}$ act as accessory adhesion molecules in interactions between granulocytes and endothelium ${ }^{26}{ }^{27}$ and in the binding of colonic adenocarcinoma to type I collagen, ${ }^{28}$ and promote the metastasis of colonic adenocarcinoma, ${ }^{29}$ including the binding of cancer cells to CEA expressing receptors on liver Kupffer cells. ${ }^{30}$ Upregulation of the CEA related molecule BGP (CD66a) has been reported as part of $\mathrm{T}$ cell activation, ${ }^{31}$ and the ability of CEA encoded HLA-A24 binding peptides to elicit the production of antitumour cytotoxic $\mathrm{T}$ cells offers a novel approach to treating CEA expressing tumours in HLA-A24 positive patients. ${ }^{32}$

\section{The link between Lewis and CEA related antigens}

Recent studies using immunoprecipitation techniques and neutrophil inhibition binding $^{726}$ have shown that the sialyl Le $^{\mathrm{x}}$ molecule, which binds to ELAM-1 and is responsible for neutrophil adhesion, is expressed on and presented by the CEA related molecules NCA-160/90 (CD66 antigens). Immunoprecipitation work carried out on normal cervical and oesophageal squamous mucosa has suggested that in these tissues $\mathrm{Le}^{\mathrm{x}}$ is expressed on a true CEA, CEA $180 . .^{33}$ In colonic carcinoma CEA, the Le $\mathrm{Le}^{\mathrm{x}}$ group Gal $\beta 1-$ 4(Fuc $\alpha 1-3)$ GlcNac $\beta 1-4$ accounts for a high proportion $(35.1 \%)$ of the desialated outer chain moieties.

\section{Non-secretory tissues and Helicobacter pylori}

The demonstration of changes in Lewis blood group and CEA related antigen expression in normal non-secretory epithelia, including squamous epithelia, ${ }^{34-39}$ non-epithelial tumours such as malignant melanoma, ${ }^{40}$ and bacteria has been relatively recent, with most attention previously centred on adenocarcinoma. Four criteria have been put forward that must be met before an adhesive function for CEA can be proved in a given tissue, namely ${ }^{41}$ : (1) expression must be membranous; (2) enzymatic removal of membranous CEA must inhibit adhesion; (3) the N-terminal domain of CEA must be present; and (4) adhesion must occur in conjunction with CD44. Evidence for an adhesive function for these molecules in general cannot be disputed, and it seems reasonable to argue that these molecules will fulfil an adhesive role on whatever cell they are found capacitated by membranous expression.

What relative importance they have in maintaining the integrity of-for example, the normal squamous mucosa, and what influence loss of expression with malignant transformation has on tumour dissemination are uncertain. Adhesion molecules are now classed into four types: integrins, cadherins, immunoglobulins, and selectins, ${ }^{42}$ of which integrins and cadherins comprise the main adhesion molecules expressed by normal and transformed epithelial cells. CEA related molecules are members of the C-2 set of the immunoglobulin superfamily, which includes ICAM-1 and ICAM- $2^{43}{ }^{44}$ and the Fc receptor. BGP binding is reportedly temperature and calcium dependent - a property associated more with cadherins. The cadherins are transmembranous calcium dependent cell-cell adhesion receptors that connect cells through homophilic interactions. ${ }^{45}$ Of the four types of cadherin, E-cadherin (epithelial cadherin, uvomorulin) is a $120 \mathrm{kDa}$ protein that is expressed on epithelial cells. Loss of E-cadherin expression leads to the dissociation of cells from coherent tissues and there is a causal relation between downregulation of E-cadherin in tumour cells and the acquisition of an invasive phenotype. ${ }^{45-47}$ E-cadherin is expressed strongly at cell-cell boundaries in normal oesophageal squamous epithelium, except in the most superficial layer. ${ }^{48-50}$ When cadherins are functionally expressed, the inactivation of other cell-cell adhesion molecules has little effect, ${ }^{51}$ and therefore cadherins have been put forward as having the major role in intercellular physical adhesion. By transfecting CEA negative carcinoma cell lines with CEA DNA, it was shown recently that CEA exerted a direct effect on the adhesive specificity of colorectal tumour cells by decreasing the expression of 
key integrin and cadherin adhesion molecules. ${ }^{52}$

The evidence for a more major role for Lewis antigens, in particular sialyl Lewis, is more compelling, owing to the model of polymorph adhesion and extravasation as a paradigm for tumour cell dissemination. ${ }^{8}$ Polymorphs are remarkably invasive cells. It has been suggested that the mechanisms by which these cells migrate out of the vascular space and into surrounding tissue may provide some insight into the invasive characteristics of metastatic tumours. The selectin ELAM-1 is an inducible molecule on endothelial cells that has specificity for the sialyl Lewis ${ }^{x}$ carbohydrate antigen upregulated on the surface of polymorphs during inflammation. This mechanism is the primary one of several involved in the margination of neutrophils at sites of inflammation. The finding that adenocarcinomas and some better differentiated squamous carcinomas express sialyl Lewis ${ }^{\mathrm{x}}$ suggests that tumour cells could localise to ELAM-1 at sites of inflammation. ${ }^{38}$

Lewis blood group antigens are expressed on human gastric epithelium and on surface glycoconjugate structures of $H$ pylori, suggesting a role in the complex mechanism of binding of bacteria to mucosa. Although autoimmune mechanisms induced by bacterial Lewis expression have been proposed to cause gastritis, a more recent study has shown that the grade of gastritis is unrelated to $H$ pylori Lewis expression (which seems to correspond to host Lewis phenotype $)^{53}$ and that epitopes other than Lewis antigens are the autoimmune targets. ${ }^{54}$

\section{The future}

The pragmatic consequences of research into adhesion molecules is the promise of the ability to treat and diagnose neoplastic and nonneoplastic pathological conditions in a better manner. This requires a full understanding of the pathways of synthesis and expression of adhesion molecules. For the CEA related family, the development of anti-CEA antibodies raised against synthetic peptides should increase the availability of specific antibodies for immunotherapy, although a number of problems exist, such as crossreactivity by unwanted cells, modulation, differential glycosylation, masking or loss of antigen by tumour cells, and immunogenicity by administered heterologous antibodies. Another interesting approach is the activation of the immune system against tumours by administering anti-idiotype antibodies, which mimic a tumour antigen, such as CEA. CEA expression could be manipulated by administering blocking antibodies or by the therapeutic upregulation of CEA on the cell surface.

1 Coon JS, Weinstein RS. Blood group related antigens as markers of malignant potential and heterogeneity in human carcinomas. Hum Pathol 1986;17:1089-106.

2 Kerr MA, McCarthy NC. A carbohydrate differentiation antigen of granulocytes, brain and many tumours. Biochem Soc Trans 1985;13:424-6.

3 McCarthy NC, Simpson JRM, Coghill G, et al. Expression in normal adult, fetal and neoplastic tissues of a carbohydrate differentiation antigen recognised by anti-
granulocyte mouse monoclonal antibodies. $\mathcal{F}$ Clin Pathol granulocyte mo
4 Fox N, Damjanov I, Knowles BB, et al. Immunohistochemical localisation of the mouse stage specific embryonic antigen 1 in human tissues and tumours. Cancer Res 1983; 43:669-78.

5 Eggens I, Fenderson B, Toyokuni T, et al. Specific interaction between $\mathrm{Le}^{\mathrm{x}}$ and $\mathrm{Le}^{\mathrm{x}}$ determinants. $\mathrm{f}$ Biol Chem 1989;264:9476-84.

6 Lindner J, Rathgen FG, Schachner M. L1 mono and polyclonal antibodies modify cell migration in early postnatal mouse cerebellum. Nature 1983;305:427-34.

7 Stocks SC, Kerr MA. Neutrophil adhesion due to Le'. Histochem f 1992;24:811-26.

8 Smith CW, Anderson DC. PMN adhesion and extravasation as a paradigm for tumour cell dissemination. Cancer Metastasis Rev 1991;10:61-78.

9 Lauri D, Needham L, Martin-Padura I, et al. Tumour cell adhesion to endothelial cells: endothelial leukocyte adhesion molecule-1 as an inducible adhesive receptor specific for colon carcinoma. F Natl Cancer Inst 1991;83:1321-4.

10 Berg EL, Robinson MK, Mansson O, et al. A carbohydrate domain common to both sialyl $\mathrm{Le}(\mathrm{a})$ and sialyl $\mathrm{Le}(\mathrm{x})$ is recognised by the endothelial cell leukocyte adhesion molecule ELAM-1. F Biol Chem 1991;266:14869-72.

11 Majuri M, Mattila LP, Renkonen R. Recombinant E-selectin protein mediates tumor cell adhesion via sialyl-Le(a) and sialyl-Le(x). Biochem Biophys Res Commun 1992;182:1376-82.

12 Takada A, Ohmori K, Takahashi N. Adhesion of human cancer cells to vascular endothelium mediated by a carbohydrate antigen sialyl Lewis A. Biochem Biophys Res Commun 1991;179:713-19.

13 Brodt P, Fallavollita L, Bresalier RS, et al. Liver endothelial E-selectin mediates carcinoma cell adhesion and promotes liver metastasis. Int $\mathcal{F}$ Cancer 1997;71:612-19.

14 Nakamori S, Kameyama M, Imaoka S, et al. Involvement of carbohydrate antigen sialyl Lewis ${ }^{\mathrm{x}}$ in colorectal cancer metastsis. Dis Colon Rectum 1997;40:420-35.

15 Satoh H, Ishikawa H, Kamma H, et al. Serum sialyl Lewis $\mathrm{x}-\mathrm{I}$ antigen levels in non-small cell lung cancer: correlation with distant metastasis and survival. Clin Cancer Res 1997; 3:495-9.

16 Gold P, Freedman SO. Demonstration of tumor-specific antigens in human colonic carcinomata by immunological tolerance and absorption techniques. 7 Exp Med 1965;121: tolerance

17 Gold P, Freedman SO. Specific carcinoembryonic antigens of the human digestive system. $\mathcal{F}$ Exp Med 1965;122:46781

18 von Kleist S, Burtin P. Localisation cellulaire d'un antigen embryonaire de tumeurs coliques humaines. Int $\mathcal{f}$ Cancer 1969;4:874-9.

19 Thompson J, Zimmermann W. The carcinoembryonic antigen gene family; structure, expression and evolution. Tumour Biol 1988;9:63-8.

20 Shively JE, Beatty JD. CEA-related antigens: molecular biology and clinical significance. Crit Rev Oncol Hematol 1985;2:355-99.

21 Buchegger F, Vacca A, Carrel S, et al. Radioimmunotherapy of human colon carcinoma by 131-I labelled monoclonal anti-CEA antibodies in a nude mouse model. Int 7 Cancer 1988;41:127-34.

22 Bertoglio S, Benevento A, Percivale P, et al. Radioimmunogold surgery benefits in carcinoembryonic antigen directed second-look surgery in the asymptomatic patient after curative resection of colorectal cancer. Semin Surg Oncol 1998; 15:263-7.

23 Oikawa S, Inuzuka C, Kuroki M, et al. Cell adhesion activity of non-specific cross-reacting antigen (NCA) and carcinoembryonic antigen (CEA) expressed on CHO cell surface: homophilic and heterophilic adhesion. Biochem Biophys Res Commun 1989;64:39-45.

24 Rojas M, Fuks A, Stanners CP. Biliary glycoprotein (BGP), a member of the immunoglobulin supergene family, functions in vitro as a Ca-dependent intercell
molecule. Cell Growth Differ 1990;1:527-33.

25 Leusch HG, Drzeniek Z, Hefta SA, et al. The putative role of members of the CEA-gene family (CEA, NCA and BGP) as ligands for the bacterial colonisation of different human epithelial tissues. Int $\mathcal{F}$ Med Microbiol 1991;275: 118-22.

26 Stocks SC, Albrechtsen M, Kerr MA. Expression of the acetyllactosamine, $\mathrm{Le}^{\mathrm{x}}$ ) on putative neutrophil adhesion molecules CR3 and NCA-160. Biochem f 1990;268:27580 .

27 Kuijpers TW, Hoogerwerf M, van der Laan LJ. CD66 nonspecific cross reacting antigens are involved in neutrophil specific cross reacting antigens are involved in neutrophil
adherence to cytokine-activated endothelial cells. $\mathcal{F ~ C e l l ~ B i o l ~}$ adherence to cytokine

28 Pignatelli M, Durbin H, Bodmer WF. Carcinoembryonic antigen functions as an accessory adhesion molecule mediating colon epithelial cell-collagen interactions. Proc Natl Acad Sci USA 1990;87:1541-5.

29 Yoshioka T, Masuko T, Kotanagi H, et al. Homotypic adhesion through carcinoembryonic antigen plays a role in hepatic metastasis development. Fpn f Cancer Res 1998;89: 177-85.

30 Hostetter RB, Cambell DE, Chi K. Carcinoembryonic antigen enhances the metastatic potential of human colorectal carcinoma. Arch Surg 1990;25:300-4.

31 Kammerer R, Hahn S, Singer BB, et al. Biliary glycoprotein (CD66a) a cell adhesion molecule of the immunoglobulin superfamily on human lymphocytes: structure, expression 
and involvement in T cell activation. Eur f Immunol 1998; 28:3664-74.

32 Nukaya I, Yasumoto $M$, Iwasaki $T$, et al. Identification of HLA-A24 epitope peptides of carcinoembryonic antigen which induce tumour reactive cytotoxic T lymphocytes. In f Cancer 1999;80:92-7.

33 Stocks SC, Hopwood D, Sanders DSA, et al. The expression of Lewis ${ }^{x}$ on carcinoembryonic antigen (CEA)-related glycoproteins of normal and inflamed oesophageal squamous mucosa. Glycosylation and Disease 1994;1:27985.

34 Sanders DSA, Kerr MA, Hopwood D, et al. Expression of the 3-fucosyl N-acetyllactosamine (CD15) antigen in normal, metaplastic, dysplastic, and neoplastic squamous epithelia. F Pathol 1988;154:255-62.

35 Sanders DSA, Milne DM, Kerr MA. The expression of Lewis $^{\mathrm{a}}$ and Lewis ${ }^{\mathrm{b}}$ antigens reflects changes in fucosylation between normal and neoplastic cervical squamous epithelium. F Pathol 1990;162:23-8.

36 Sanders DSA, Kerr MA, Hopwood D, et al. Expression of the CD15 antigen is a marker of cellular differentiation in cervical intra-epithelial neoplasia (CIN). 7 Pathol 1988; 155:207-12.

37 Sanders DSA, Stocks SC, Milne DM, et al. Membranous expression of carcinoembryonic antigen (CEA) in the normal cervical squamous mucosa. F Pathol 1992;167:77-82.

38 Sanders DSA, Ferryman SR, Bryant FJ, et al. Patterns of CEA-related antigen expression in invasive squamous carcinoma of the cervix. F Pathol 1993;171:21-6.

39 Sanders DSA, Wilson CA, Bryant FJ, et al. Classification and localisation of carcinoembryonic antigen (CEA) related antigen expression in normal oesophageal squamous mucosa and squamous carcinoma. Gut 1994;35: $1022-5$.

40 Sanders DSA, Evans AT, Allen CA, et al. Classification of CEA related positivity in primary and metastatic malignant melanoma. F Pathol 1994;172:343-8.

41 Ishii S, Steele G, Ford R, Paliotti G, et al. Normal colonic epithelium adheres to carcinoembryonic antigen and type IV collagen. Gastroenterology 1994;106:1242-50.
42 Hynes RO. Integrins; versatility, modulation and signaling in cell adhesion. Cell 1992;69:11-25.

43 Staunton DE, Dustin ML, Springer TA. Functional cloning of ICAM-2, a cell adhesion ligand for LFA-1 homologous to ICAM-1. Nature 1989;339:61-4.

44 Staunton DE, Marlin SD, Stratowa C, et al. Primary structure of ICAM-1 demonstrates interaction between members of the immunoglobulin and integrin supergene families. Cell 1988;52:925-33.

45 Takeichi $M$. Cadherin cell adhesion receptors as a morphogenetic regulator. Science 1991;251:1451-5.

46 Vestweber D, Kemler R. Identification of a putative cell adhesion domain of uvomorulin. EMBO $\mathcal{F} 1985 ; 4: 3393-8$.

47 Frixen UH, Behren J, Sachs ME, et al. E-cadherin mediated cell-cell adhesion prevents invasiveness of human carcinoma cells. F Cell Biol 1991;113:173-85

48 Sanders DSA, Bruton R, Darnton SJ, et al. Sequential changes in cadherin-catenin complexes in heterogeneity of primary oesophageal squamous carcinoma. Int 7 Cancer 1998;79:573-9.

49 Shiozaki H. E-cadherin in human cancers. Am f Pathol 1991;139:17-23.

50 Williams HK, Sanders DSA, Jankowski J, et al. Expression of cadherins and catenins during in epithelial dysplasia and oral squamous cell carcinoma. F Oral Pathol Med 1998;27: 308-17.

51 Duband J, Dufour S, Hatta K, et al. Adhesion molecules during somatogenesis in the avian embryo. $\mathcal{F}$ Cell Biol 1987; 104:1361-74

52 Nigam AK, Wrba F, Durbin PB, et al. Role of CEA in colorectal tumour cell adhesion [abstract]. F Pathol 1994;172: 96 .

53 Wirth HP, Yang MQ, Peek RM, et al. Helicobacter pylori Lewis expression is related to the host Lewis phenotype. Gastroenterology 1997;113:1091-8.

54 Faller G, Steininger H, Appelmelk B, et al. Evidence of novel pathogenic pathways for the formation of antigastric
autoantibodies in Helicobacter pylori gastritis. 7 Clin Pathol 1998;51:244-9. 